\title{
ANÁLISE DA ESPECIALIZAÇÃO E DO FLUXO DE COMÉRCIO EXTERIOR DO ESTADO DE MINAS GERAIS
}

\author{
Patrícia Alves Rosado Pereira* \\ Juliana Galli da Costa* \\ Simone de Faria Narciso Shiki*
}

\begin{abstract}
Resumo: O presente trabalho analisa a especialização e o fluxo do comércio exterior de Minas Gerais no período de 1997 a 2014. Para análise, foram utilizados os índices de vantagem comparativa revelada (Balassa), índice de vantagem comparativa revelada simétrica (Laursen) e o índice de comércio intra-indústria (Grubbel e Lloyd). Quanto aos resultados, constatou-se que o estado, apesar de certa diversificação, concentra-se em poucos produtos, sobretudo, agrícolas, minerais e metais. Nesse sentido, os produtos que apresentaram vantagem comparativa foram os setores relativamente menos intensivos em capital, especialmente, produtos básicos, como os setores de "café, chá, mate e especiarias" e "Minérios, escórias e cinzas", bem como, alguns semimanufaturados do setor de "Ferro fundido, ferro e aço". Desta forma, conclui-se que, o comércio de Minas Gerais possui vantagem comparativa revelada em produtos de baixo valor agregado, e seu comércio é do tipo interindústria.
\end{abstract}

Palavras-chave: Minas Gerais. Vantagem Comparativa. Comércio Intraindústria

\begin{abstract}
The present paper analyzes the specialization and foreign trade flow of Minas Gerais from 1997 to 2014. For analysis, the revealed comparative advantage indices were used (Balassa), symmetric revealed comparative advantage index (Laursen) and the intra-industry trade index (Grubbel and Lloyd). As for the results, it was found that the state, despite some diversification, concentrated in a few products, mainly agricultural, minerals and metals. In this sense, the products that presented comparative advantage were the sectors relatively with less capital-intensive, especially, basic products, like the sectors of "coffee, tea, mate and spices" and "Ores, slag and ash" as well as some semi -billed of the sector of "Cast iron, iron and steel." Thus, it was concluded that trade in Minas Gerais has a revealed comparative advantage in low value-added products, and its trade is the inter-industry type.
\end{abstract}

Keywords: Minas Gerais. Comparative Advantage. Intra-industry trade.

\section{JEL: O12, L6, O14, G01}

\footnotetext{
* Universidade Federal de SãoJ oão del-Rei
} 


\section{Introdução}

O processo de globalização intensificou o fluxo comercial entre os países, sobretudo, a partir de 1990, expondo as nações e os agentes econômicos à competitividade internacional. Neste contexto, proporciona maior acirramento da concorrência internacional, maior integração entre as estruturas produtivas das economias domésticas tendo de um lado os países desenvolvidos que apresentaram evolução na produção de bens com alto valor agregado e de outro lado os países subdesenvolvidos que, em geral, se especializaram na produção de bens primários. Nessa nova conjuntura os países desenvolvidos apresentam uma estrutura produtiva diversificada e homogênea, diferente da que se encontra nos países subdesenvolvidos que apresentam uma estrutura heterogênea, gerando uma deterioração dos termos de troca conforme colocado pela CEPAL.

Apesar de o Brasil ser um dos poucos países subdesenvolvidos que completou todo o processo de industrialização, desde a produção de bens de consumo não duráveis até a produção de bens de capital, alguns estudos mostram que a partir de 2006 o país apresenta uma reprimarização na pauta de exportações e uma perda na produtividade industrial (BRESSER-PEREIRA e MARCONI, 2008; MARCONI, 2013). Para Cano (2012), a indústria nacional não se encontra em condições de competitividade externa e passa por um processo de desindustrialização, sendo os seguintes fatores responsáveis por esse quadro: câmbio valorizado, abertura comercial, taxa de juros elevada, investimento estrangeiro direto de caráter especulativo e economia mundial em recessão.

No Brasil, as exportações atingiram, em 2013, o valor de US\$ 242 bilhões, uma queda de $0,2 \%$ em relação ao ano anterior. Quanto às importações, estas foram na ordem de US\$239,7 bilhões, um crescimento de 7,4\% se comparado com o ano de 2012, em que as principais aquisições são bens de capital (MDIC, 2014).

Dentre os estados brasileiros, Minas Gerais é o segundo maior exportador, no comércio mundial, estando à sua frente somente o estado de São Paulo. De acordo com dados do MDIC (2014), as exportações mineiras atingiram US\$ 33,4 bilhões para o ano de 2013, uma participação de 13,8\% no total exportado pelo país.

Considerando a importância do comércio de Minas Gerais para a economia brasileira, verifica-se a relevância de uma análise do desempenho do fluxo industrial de comércio exterior neste estado. Assim, questiona-se, em quais grupos de produtos o estado de Minas Gerais apresenta maiores vantagens comparativas reveladas; e em qual tipo de comércio ocorre, o intra-indústria ou inter-indústria no período de 1997 a 2014.

É relevante conhecer com quais produtos houve vantagem comparativa. A busca da manutenção e da ampliação de mercados tem sido uma constante nas estratégias implementadas pelos países, em razão de crescente competitividade a qual estão expostos.

O conhecimento do comércio dos setores produtivos do Estado possibilita a adoção de políticas de apoio à modernização dessas indústrias, tanto por parte 
do Governo quanto do setor privado, com o objetivo de ampliar o comércio internacional entre o Brasil e os demais países.

\subsection{Referencial teórico}

Várias teorias buscam explicar as origens e os padrões do comércio internacional, dentre elas, destacam-se, as teorias de David Ricardo e de Heckscher-Ohlin. Esta última se distingue da primeira, ao considerar dois fatores de produção, por exemplo, trabalho e capital, no qual explica a vantagem comparativa entre as nações em virtude da diferença nas dotações de fatores. De outro modo, o modelo de Ricardo supõe apenas um fator de produção, o trabalho, em que as diferenças internacionais nas funções de produção é que determinam a vantagem comparativa (HIDALGO, 1985).

Com o intuito de demonstrar o desempenho relativo das exportações de determinado produto, em uma categoria de produtos individuais, Bela Balassa criou, em 1965, a Teoria das Vantagens Comparativas Reveladas. Esta teoria está baseada no modelo ricardiano, com o objetivo de diagnosticar se uma nação vem obtendo vantagens ou desvantagens comparativas reveladas (VCR) na produção de um determinado bem e posteriormente, aprofundada por Lafay, em 1987. Esta teoria utiliza dados de preços pós-comércio e é um dos métodos mais utilizados para determinar a competitividade de um país. Desta forma, seu cálculo está baseado em dados observados após ocorrer o comércio, no qual revele vantagens comparativas. Balassa considerou o desempenho relativo das exportações de uma nação em uma categoria de produtos individuais refletindo suas vantagens comparativas reveladas naquele setor. Portanto, descrevem os padrões de comércio existentes, mas não identifica se são ótimos padrões ou não (MAIA; RODRIGUES; SILVA, 2004).

Segundo Rubin e Rondinel (2004 apud SIQUEIRA; PINHA, 2012), este índice está baseado nos diferentes custos relativos existentes entre as nações, levando à especialização na produção de certos produtos e importações de outros. Assim, cada país se especializaria na produção e exportação da commodity em que é relativamente mais eficiente e importaria a que possui um custo relativamente maior.

Desta forma, a Teoria das Vantagens Comparativas Reveladas demonstra o desempenho relativo das exportações de determinado bem, em uma categoria de produtos individuais, com o objetivo de diagnosticar se o país vem apresentando vantagens ou desvantagens comparativas reveladas na produção de determinada mercadoria (MAIA; RODRIGUES; SILVA, 2004).

Portanto, contrapondo-se as teorias tradicionais, novas abordagens sobre o comércio internacional foram formuladas, baseadas nas hipóteses de economias de escala, diferenciação de produtos e concorrência monopolística (GONÇALVES, 2005; KRUGMAN; OBSTFELD, 2010; GONÇALVES et al., 1998). Desta forma, foram criadas com o intuito de obter ganhos de competitividade no comércio exterior, no qual está inserido em um contexto de crescente dinamismo (FERREIRA; PINTO, 2008). 
Neste sentido, estas novas abordagens foram consideradas como a nova teoria do comércio internacional, supondo concorrência monopolística (produtos diferenciados), e não concorrência perfeita (produtos homogêneos), como postula as teorias clássicas (KRUGMAN; OBSTFELD, 2010).

Conforme Krugman e Obstfeld (2010), em um modelo de concorrência monopolística, o comércio internacional se dará nos dois sentidos, dentro do mesmo setor, conhecido como comércio intra-indústria. Portanto, não reflete a vantagem comparativa, diferentemente do comércio inter-indústria, que é baseado na teoria Heckscher-Ohlin.

Para Vasconcelos (2003), o comércio intra-indústria é o comércio entre dois países, ou grupo de países, que exportam e importam bens de um mesmo segmento industrial, no qual está baseado nas hipóteses de diferenciação de produtos, economias de escala e competição monopolística. De outro modo, no comércio inter-indústria essa troca se realiza em diferentes setores, fundamentado nas vantagens comparativas.

Além disso, o comércio intra-indústria, baseado na diferenciação do produto, pode ser vertical ou horizontal. A vertical atribuída à qualidade dos insumos, ou seja, esta diferenciação aumenta quando variedades distintas de produtos têm diferentes finalidades. A horizontal relacionada à característica de uso do produto ou de seus atributos, isto é, esta diferenciação de produtos aumenta quando variedades diferentes de um bem são, de certa maneira, similares na qualidade (GREENAWAY; MILNER, 1999; GREENAWAY; HINE; MILNER, 1995 apud VASCONCELOS, 2004).

O comércio intra-indústria gera ganhos adicionais do comércio mundial, pois abarca mercados maiores, reduzindo o número de bens que produz, em uma escala maior, a custos menores. E, ao mesmo tempo, propicia maior variedade de bens para os consumidores domésticos (KRUGMAN; OBSTFELD, 2010). Este comércio, entre setores semelhantes, depende da capacidade de produção de bens diferenciados, possibilitando ao consumidor escolher o produto conforme sua preferência e de acordo com o preço. Desta forma, fatores como barreira à entrada, economias de escala, diferenciação dos produtos e progresso tecnológico, tornam-se relevantes, sobretudo, num mercado cada vez mais competitivo e exigente.

\section{METODOLOGIA}

\subsection{Vantagens Comparativas Reveladas}

Neste trabalho, utiliza-se o indicador de Vantagem Comparativa Revelada (VCR), desenvolvido por Balassa (1965, apud Hermida e Xavier, 2011), permite captar se o país possui vantagem comparativa em determinado setor, com base na participação desse país nas exportações mundiais totais. O índice de vantagem comparativa revelada é definido pela seguinte relação:

$\mathrm{VCR}_{\mathrm{ij}}=\left(\mathrm{X}_{\mathrm{ij}} / \mathrm{X}_{\mathrm{j}}\right) /\left(\mathrm{X}_{\mathrm{iw}} / \mathrm{X}_{\mathrm{w}}\right)$ 
Onde:

$\mathrm{X}_{\mathrm{ij}}$ - representa o valor das exportações do produto i do estado de Minas Gerais $\mathrm{j} ;$

$\mathrm{X}_{\mathrm{j}}$ - representa o valor total das exportações do estado de Minas Gerais j;

$\mathrm{X}_{\mathrm{iw}}$ - representa o valor das exportações do produto i do Brasil/Mundo w; e

$\mathrm{X}_{\mathrm{w}}$ - representa o valor total das exportações do Brasil/Mundo w.

O índice $\mathrm{VCR}_{\mathrm{ij}}$ é uma razão de proporções, cujo resultado é obtido por meio da divisão da participação das exportações do produto i na pauta de exportações do estado j pela participação do mesmo produto i na pauta nacional/mundial de exportações, ou seja, seu resultado revela se determinado estado possui vantagens comparativas ao comparar seu peso dentro da pauta exportadora com a nacional/mundial. O índice $\mathrm{VCR}_{\mathrm{ij}}$ pode variar de zero a infinito:

Se $\mathrm{VCR}_{\mathrm{ij}}>1$ - o estado possui vantagem comparativa revelada naquele produto i; e

Se $\mathrm{VCR}_{\mathrm{ij}}<1$ - o estado possui desvantagem comparativa revelada naquele produto i.

Esse indicador apresenta a desvantagem de não considerar as importações, o que não permitirá analisar as distorções causadas por medidas protecionistas dos países importadores e aos efeitos das diferenças na demanda em cada país (Vasconcelos, 2003).

\section{2 Índice de Comércio Intra-indústria}

Um indicador que permite classificar o comércio exterior em interindustrial ou intra-industrial é o índice de comércio intra-indústria (CIIA) desenvolvido por Grubbel e Lloyd (1975), sendo aplicado por produto e indústria e para toda a economia e pode ser, em termos agregados, representado da seguinte forma:

CIIA $=1-\sum\left|\mathrm{X}_{\mathrm{i}}-\mathrm{M}_{\mathrm{i}}\right| / \sum\left(\mathrm{X}_{\mathrm{i}}+\mathrm{M}_{\mathrm{i}}\right)$

Em que $\mathrm{X}_{\mathrm{i}}$ representa as exportações do produto $\mathrm{i}$ e $\mathrm{M}_{\mathrm{i}}$ representa as importações do produto pelo estado de Minas Gerais. O valor numérico desse índice encontra-se no intervalo [0,1]. Quando o CIIA for igual a zero, ocorre o comércio inter-indústria, aquele que segue os postulados do teorema de Heckscher-Ohlin. Por outro lado, se for igual a um, todo o comércio é intraindústria.

Analogamente, o índice de comércio intra-indústria (CIIA) ao nível de cada indústria ou produto i érepresentado por: 
Esse índice está contido no intervalo [0,1]. Quando todo o comércio for explicado pelo comércio inter-indústria, o índice é zero, sendo, neste caso, ou as exportações ou as importações de cada bem i iguais a zero. Em sentido oposto, quando todo o comércio for intra-indústria, o índice será igual a um e o valor das exportações seria igual ao valor das importações de cada bem i. Para identificar o tipo de especialização comercial existente, considera-se a existência de comércio intra-indústria nos casos em que o índice for maior que 0,50 (CORREA; LOES, 1994 apud SILVA; ILHA, 2004).

Os dados utilizados, referente às exportações e importações de Minas Gerais e do Brasil, foram disponibilizados pela Secretaria de Comércio Exterior (SECEX) do Ministério do Desenvolvimento, Indústria e Comércio Exterior (MDIC), através do Sistema de Análise das Informações de Comércio Exterior (Aliceweb), Free on Boand (FOB) em dólares, por capítulo, de acondo com a Nomenclatura Comum do Mercosul (NCM), no qual tem por base o Sistema Harmonizado (SH). Quanto à base de dados internacional, estes foram extraídos do COMTRADE, por meio da plataforma World Integrated Trade Solution (WITS), no qual disponibiliza informações sobre o comércio mundial. Além disso, de 1997 a 2014, adotou-se diferentes nomenclaturas: SH 1996 (1997 a 2001); SH 2002 (2002 a 2006); SH 2007 (2007 a 2011) e; SH 2012 (2012 a 2014), obtendo, desta forma, dados mais completos e atuais das exportações mundiais.

\section{RESULTADOS}

No período de 1997 a 2014, o estado de Minas Gerais foi o segundo maior exportador, no comércio mundial, estando a sua frente somente o Estado de São Paulo. Exceto de 2001 a 2003, em que obteve a terceira colocação na pauta das exportações, trocando sua posição com o Estado do Rio Grande do Sul. Deste modo, verifica-se que, Minas Gerais possui grande relevância econômica para o país e, sua participação no período foi, em média, $12,58 \%$. Destaque para o ano de 2011, com um percentual de 16,17\% das exportações do país. Ademais, as exportações do país estão concentradas em três estados: São Paulo, Minas Gerais e Rio Grande do Sul, que juntos, representam, em média, 52,77\%, para todo período. (MDIC, 2014).

A tabela 1, a seguir, refere-se à Balança Comercial de Minas Gerais e do Brasil. No qual, demonstra o desempenho superavitário e ascendente de Minas gerais, sobretudo, a partir de 2010, em que seu saldo ultrapassou os US\$21,3 bilhões. Salienta-se, portanto, o ano de 2011, no qual seu valor foi superior a US\$28,4 bilhões, valor este próximo ao saldo nacional (US\$ 29,8 bilhões) para o mesmo ano, demonstrando um resultado positivo para os mineiros. O país, entretanto, obteve resultados mais expressivos em seus saldos de 2005 a 2007, atingindo a cifra acima dos US\$ 40 bilhões. 
Além disso, de 1997 a 2000, o saldo comercial do Brasil foi negativo e, contrapondo-se ao resultado nacional, Minas Gerais obteve um desempenho positivo, no qual seu saldo comercial foi superavitário para todo o período (1997 a 2014), refletindo sua relevância no comércio internacional, bem como para o país. Observou-se, que, a partir de 1999, com a adoção do câmbio flexível, houve uma reversão no saldo nacional, com uma redução em seu déficit, até se tornar superavitário em 2001 e nos demais anos, exceto em 2014. Ademais, verificou-se uma redução no saldo do Brasil, sobretudo, em 2013, ano em que o país enfrentou uma crise interna, ou seja, insatisfações políticas e grandes manifestações populares, refletindo negativamente na economia nacional, bem como, no estado de Minas Gerais, porém, neste último, em proporções menores.

Desta forma, demonstra uma evolução do Estado de Minas Gerais nas relações comerciais internacionais. Seu desempenho positivo e crescente revela a eficácia de políticas comerciais adotadas pelo Estado, que objetivam o fomento a cultura do comércio internacional; capacitação de profissionais; desenvolvimento de polos logísticos; promoção de investimentos em infraestrutura; fomento na diversificação e agregação de valor à pauta exportadora; bem como um crescimento sustentável, expandindo e intensificando a inserção do estado no comércio internacional; conforme o Mapa Estratégico do Comércio Exterior de Minas Gerais, lançado em 2010. Além dos investimentos em setores pontuais e estratégicos.

O fluxo de comércio exterior de Minas Gerais foi caracterizado em 16 capítulos principais: 02) Carnes e miudezas, comestíveis; 09) Café, chá, mate e especiarias; 12) Sementes e frutos oleaginosos; grãos, sementes etc.; 17) Açúcares e produtos de confeitaria; 25) Sal; enxofre; terras e pedras; gesso, cal e cimento; 26) Minérios, escórias e cinzas; 28) Produtos químicos inorgânicos; compostos inorgânicos ou orgânicos de metais preciosos, etc.; 30) Produtos farmacêuticos; 47) Pastas de madeira ou de outras matérias fibrosas celulósicas etc.; 68) Obras de pedra, gesso, cimento, amianto, mica ou de matérias semelhantes; 71) Pérolas naturais ou cultivadas, pedras preciosas etc.; 72) Ferro fundido, ferro e aço; 73) Obras de ferro fundido, ferro ou aço; 84) Reatores nucleares, caldeiras, máquinas, aparelhos e instrumentos mecânicos, e suas partes; 85) Máquinas, aparelhos e materiais elétricos, etc. e; 87) Veículos automóveis, tratores, ciclos e outros veículos terrestres, suas partes e acessórios.

Tabela 1 - Balança Comencial de Minas Gerais e do Brasil, 1997 a 2014

\begin{tabular}{c|c|c|c|c|c|c|c|c}
\hline \multirow{2}{*}{ Ano } & \multicolumn{5}{|c|}{ Minas Gerais } & \multicolumn{3}{c}{ Brasil } \\
\cline { 2 - 9 } & Exportação & $\%$ & Importação & $\%$ & Saldo & Exportação & Importação & Saldo \\
\hline 1997 & 7.227 .701 .328 & 13,64 & 3.583 .740 .235 & 6,00 & 3.643 .961 .093 & 52.982 .725 .829 & 59.747 .227 .088 & -6.764 .501 .259 \\
\hline 1998 & 7.590 .666 .898 & 14,84 & 3.548 .576 .885 & 6,14 & 4.042 .090 .013 & 51.139 .861 .545 & 57.763 .475 .974 & -6.623 .614 .429 \\
\hline 1999 & 6.382 .017 .158 & 13,29 & 2.935 .695 .218 & 5,95 & 3.446 .321 .940 & 48.012 .789 .947 & 49.301 .557 .692 & -1.288 .767 .745 \\
\hline 2000 & 6.712 .298 .519 & 12,18 & 2.778 .805 .082 & 4,98 & 3.933 .493 .437 & 55.118 .919 .865 & 55.850 .663 .138 & -731.743 .273 \\
\hline 2001 & 6.059 .713 .464 & 10,40 & 3.001 .477 .890 & 5,40 & 3.058 .235 .574 & 58.286 .593 .021 & 55.601 .758 .416 & 2.684 .834 .605 \\
\hline
\end{tabular}




\begin{tabular}{l|l|l|l|l|l|l|l|l}
2002 & 6.353 .218 .803 & 10,51 & 2.514 .642 .986 & 5,32 & 3.838 .575 .817 & 60.438 .653 .035 & 47.242 .654 .199 & 13.195 .998 .836 \\
\hline 2003 & 7.440 .403 .270 & 10,16 & 2.431 .952 .029 & 5,03 & 5.008 .451 .241 & 73.203 .222 .075 & 48.325 .566 .630 & 24.877 .655 .445 \\
\hline 2004 & 10.007 .224 .885 & 10,35 & 2.987 .333 .176 & 4,75 & 7.019 .891 .709 & 96.677 .498 .766 & 62.835 .615 .629 & 33.841 .883 .137 \\
\hline 2005 & 13.514 .972 .369 & 11,40 & 3.935 .679 .151 & 5,35 & 9.579 .293 .218 & 118.529 .184 .899 & 73.600 .375 .672 & 44.928 .809 .227 \\
\hline 2006 & 15.658 .215 .268 & 11,36 & 4.858 .644 .258 & 5,32 & 10.799 .571 .010 & 137.807 .469 .531 & 91.350 .840 .805 & 46.456 .628 .726 \\
\hline 2007 & 18.355 .152 .652 & 11,43 & 6.504 .847 .333 & 5,39 & 11.850 .305 .319 & 160.649 .072 .830 & 120.617 .446 .250 & 40.031 .626 .580 \\
\hline 2008 & 24.444 .431 .881 & 12,35 & 10.483 .316 .005 & 6,06 & 13.961 .115 .876 & 197.942 .442 .909 & 172.984 .767 .614 & 24.957 .675 .295 \\
\hline 2009 & 19.517 .677 .395 & 12,76 & 7.350 .815 .024 & 5,76 & 12.166 .862 .371 & 152.994 .742 .805 & 127.722 .342 .988 & 25.272 .399 .817 \\
\hline 2010 & 31.224 .473 .218 & 15,46 & 9.967 .232 .720 & 5,48 & 21.257 .240 .498 & 201.915 .285 .335 & 181.768 .427 .438 & 20.146 .857 .897 \\
\hline 2011 & 41.392 .937 .313 & 16,17 & 13.028 .493 .635 & 5,76 & 28.364 .443 .678 & 256.039 .574 .768 & 226.246 .755 .801 & 29.792 .818 .967 \\
\hline 2012 & 33.248 .659 .560 & 13,71 & 12.054 .596 .228 & 5,40 & 21.194 .063 .332 & 242.578 .013 .546 & 223.183 .476 .643 & 19.394 .536 .903 \\
\hline 2013 & 33.436 .933 .060 & 13,81 & 12.343 .918 .744 & 5,15 & 21.093 .014 .316 & 242.033 .574 .720 & 239.747 .515 .987 & 2.286 .058 .733 \\
\hline 2014 & 29.320 .690 .824 & 13,03 & 11.001 .994 .388 & 4,80 & 18.318 .696 .436 & 225.100 .884 .831 & 229.137 .077 .886 & -4.036 .193 .055 \\
\hline
\end{tabular}

Fonte: MDIC ( 2014).

Estes capítulos foram os mais frequentes para todo período, sobretudo nos últimos três anos (2012 a 2014), exceto o capítulo 68, que esteve entre as 15 principais commodities de 1997 a 2009, porém, nos anos seguintes manteve-se entre os 20 mais bem posicionados.

A tabela 2 representa a estrutura das exportações totais do estado mineiro, agrupados em 16 capítulos. Constatou-se que, os capítulos 09, 26 e 72, juntos, representam, em média, para todo período, $63,56 \%$ do total exportado pelo estado. Um resultado expressivo, o que significa que nossa pauta de exportações se concentra em produtos de baixo valor agregado. Especificamente, de 2012 a 2014, desdobrando estes três capítulos em oito dígitos (NCM), verificou-se que, os principais produtos exportados, em média, para os três anos selecionados são: "minérios de ferro não aglomerados e seus concentrados" (cód. 26011100, produto básico) com 95,64\%; "café não torrado, não descafeinado, em grão" (cód. 09011110, produto básico) com 99,78\% e; "ferronióbio" (cód. 72029300, produto semimanufaturado) com $44,24 \%$.

Tabela 2 - Estrutura das exportações totais de Minas Gerais, por grupo de capítulos, 1997-2014 (\%)

\begin{tabular}{l|c|c|c|c|c|c|c|c|c|c|c|c|c|c|c|c|c|c}
\hline Código & 1997 & 1998 & 1999 & 2000 & 2001 & 2002 & 2003 & 2004 & 2005 & 2006 & 2007 & 2008 & 2009 & 2010 & 2011 & 2012 & 2013 & 2014 \\
\hline 02 & 0,12 & 0,12 & 0,27 & 0,50 & 1,31 & 1,61 & 1,86 & 2,06 & 2,15 & 2,87 & 3,11 & 2,42 & 3,11 & 2,19 & 1,79 & 2,42 & 2,71 & 3,11 \\
\hline 09 & 22,98 & 19,40 & 20,49 & 14,85 & 13,84 & 12,99 & 12,42 & 12,76 & 14,21 & 13,71 & 14,06 & 12,41 & 15,00 & 13,14 & 14,02 & 11,37 & 9,27 & 14,05 \\
\hline 12 & 0,79 & 1,36 & 1,05 & 1,14 & 1,23 & 2,12 & 2,56 & 2,25 & 2,57 & 1,71 & 0,61 & 0,76 & 1,71 & 0,85 & 0,81 & 1,38 & 2,64 & 2,50 \\
\hline 17 & 0,75 & 0,43 & 0,74 & 0,15 & 1,00 & 1,48 & 1,45 & 1,45 & 1,89 & 2,46 & 1,83 & 1,43 & 3,13 & 3,20 & 3,16 & 3,85 & 3,41 & 3,12 \\
\hline
\end{tabular}




\begin{tabular}{l|c|c|c|c|c|c|c|c|c|c|c|c|c|c|c|c|c|c}
\hline 25 & 0,23 & 0,23 & 0,42 & 0,50 & 0,37 & 0,40 & 0,63 & 0,45 & 0,43 & 0,42 & 0,41 & 0,36 & 0,48 & 0,44 & 0,41 & 0,59 & 0,66 & 0,71 \\
\hline 26 & 19,07 & 24,04 & 22,90 & 24,88 & 26,37 & 26,51 & 20,39 & 19,78 & 21,75 & 23,55 & 26,27 & 29,53 & 34,19 & 43,73 & 47,39 & 43,90 & 48,77 & 42,11 \\
\hline 28 & 3,01 & 2,30 & 2,90 & 3,13 & 2,80 & 2,98 & 2,99 & 2,79 & 2,42 & 2,05 & 2,18 & 2,36 & 1,93 & 1,73 & 1,81 & 1,84 & 1,26 & 1,48 \\
\hline 30 & 0,03 & 0,05 & 0,06 & 0,06 & 0,05 & 0,04 & 0,06 & 0,06 & 0,05 & 0,05 & 0,04 & 0,16 & 0,60 & 0,52 & 0,37 & 1,12 & 1,25 & 1,50 \\
\hline 47 & 3,81 & 3,40 & 4,28 & 5,50 & 5,14 & 4,01 & 4,38 & 3,44 & 2,89 & 2,76 & 3,02 & 2,49 & 2,03 & 2,28 & 1,60 & 1,81 & 1,85 & 1,94 \\
\hline 68 & 1,12 & 1,09 & 1,11 & 0,96 & 1,08 & 1,08 & 0,85 & 0,91 & 0,77 & 0,92 & 0,97 & 0,71 & 0,63 & 0,44 & 0,34 & 0,36 & 0,36 & 0,42 \\
\hline 71 & 2,86 & 2,63 & 2,95 & 3,22 & 3,36 & 3,64 & 3,31 & 3,57 & 2,98 & 3,08 & 3,24 & 2,87 & 4,46 & 3,99 & 3,88 & 4,94 & 4,84 & 4,79 \\
\hline 72 & 18,40 & 16,93 & 17,88 & 20,63 & 18,85 & 21,11 & 25,87 & 28,12 & 27,35 & 23,02 & 21,91 & 24,31 & 14,69 & 13,29 & 12,41 & 12,74 & 9,61 & 10,72 \\
\hline 73 & 2,15 & 1,85 & 1,93 & 2,06 & 2,15 & 2,38 & 2,34 & 2,41 & 2,12 & 2,57 & 1,90 & 1,47 & 1,57 & 0,79 & 0,82 & 1,48 & 2,00 & 2,73 \\
\hline 84 & 2,73 & 2,79 & 2,77 & 2,95 & 3,09 & 2,94 & 3,06 & 3,09 & 3,04 & 3,35 & 2,99 & 2,59 & 2,31 & 1,98 & 2,01 & 2,14 & 1,92 & 1,68 \\
\hline 85 & 1,55 & 1,39 & 1,75 & 1,89 & 2,23 & 1,95 & 1,70 & 1,71 & 1,39 & 1,44 & 1,22 & 1,04 & 1,02 & 0,77 & 0,64 & 0,84 & 0,84 & 0,89 \\
\hline 87 & 13,28 & 14,56 & 12,62 & 9,69 & 7,15 & 5,10 & 6,13 & 5,82 & 5,87 & 7,31 & 7,25 & 7,60 & 6,20 & 4,67 & 3,68 & 3,22 & 3,80 & 2,92 \\
\hline Outros & 7,12 & 7,42 & 5,88 & 7,89 & 10,01 & 9,67 & 9,99 & 9,33 & 8,10 & 8,73 & 8,98 & 7,47 & 6,95 & 5,99 & 4,85 & 5,99 & 4,80 & 5,32 \\
\hline Total & 100 & 100 & 100 & 100 & 100 & 100 & 100 & 100 & 100 & 100 & 100 & 100 & 100 & 100 & 100 & 100 & 100 & 100 \\
\hline Fon & & & & & & & & & & & & & & & & & & \\
\hline
\end{tabular}

Fonte: MDIC ( 2014).

O índice de vantagem comparativa revelada, que varia de zero a infinito, no qual, valores maiores que um, refletem vantagem comparativa no comércio está ilustrado na tabela 3. Verifica-se, portanto, que os capítulos 09, 26, 28, 71, 72 e 73 apresentaram vantagem comparativa revelada em todo período analisado. Neste sentido, pode-se observar que, os capítulos 47 e 68, apresentaram vantagens até 2008 e 2009, respectivamente. Tabela 4.

De outra forma, um capítulo que chama atenção é o de produtos farmacêuticos (código 30), que apresentou uma evolução em seu índice, saltando da 49a posição (1997) para 12 ${ }^{\mathrm{a}}$ posição (2014). A partir de 2009, este processo de crescimento foi mais evidente, posicionando-se entre os 20 principais produtos. Porém, obteve vantagem comparativa revelada somente de 2012 a 2014, no qual, este produto se classifica como manufaturado, ou seja, de alto valor agregado. Revelando, assim, uma mudança, pequena, porém positiva, na estrutura produtiva do estado.

De forma semelhante o capítulo 25, também apresentou tal evolução, pulou da 25a posição (1997) para 15 $5^{\text {a }}$ posição (2014), obtendo vantagem comparativa após 2008. E fazendo um desdobramento em oito dígitos (NCM), o principal produto que representa este capítulo foi "granito cortado em blocos ou placas" (25161200, produto básico), de baixo valor agregado. O que reforça a hipótese de uma especialização baseada em bens primários.

Tabela 3 - Índice de vantagem comparativa revelada, por grupo de capítulos, de Minas Gerais em relação ao Brasil, 1997-2014

\begin{tabular}{l|l|l|l|l|l|l|l|l|l|l|l|l|l|l|l|l|l|l}
\hline Cap. & 1997 & 1998 & 1999 & 2000 & 2001 & 2002 & 2003 & 2004 & 2005 & 2006 & 2007 & 2008 & 2009 & 2010 & 2011 & 2012 & 2013 & 2014 \\
\hline
\end{tabular}




\begin{tabular}{|c|c|c|c|c|c|c|c|c|c|c|c|c|c|c|c|c|c|c|}
\hline 02 & 0,05 & 0,05 & 0,09 & 0,17 & 0,30 & 0,35 & 0,37 & 0,36 & 0,36 & 0,54 & 0,52 & 0,39 & 0,48 & 0,37 & 0,33 & 0,43 & 0,44 & 0,45 \\
\hline 09 & 4,26 & 4,03 & 4,15 & 4,87 & 6,02 & 5,89 & 6,39 & 6,52 & 6,31 & 6,05 & 6,27 & 5,62 & 5,76 & 4,91 & 4,31 & 4,58 & 4,53 & 4,84 \\
\hline 12 & 0,17 & 0,31 & 0,31 & 0,28 & 0,26 & 0,42 & 0,43 & 0,40 & 0,56 & 0,41 & 0,14 & 0,13 & 0,23 & 0,15 & 0,12 & 0,19 & 0,28 & 0,24 \\
\hline 17 & 0,21 & 0,11 & 0,18 & 0,07 & 0,24 & 0,40 & 0,46 & 0,50 & 0,55 & 0,53 & 0,56 & 0,50 & 0,56 & 0,50 & 0,53 & 0,72 & 0,69 & 0,73 \\
\hline 25 & 0,71 & 0,60 & 0,90 & 0,97 & 0,80 & 0,83 & 1,13 & 0,91 & 0,96 & 0,90 & 0,90 & 0,93 & 1,21 & 1,24 & 1,34 & 1,86 & 2,00 & 2,05 \\
\hline 26 & 3,30 & 3,55 & 3,74 & 4,21 & 4,91 & 5,02 & 4,10 & 3,65 & 3,21 & 3,33 & 3,51 & 3,12 & 3,62 & 2,86 & 2,74 & 3,20 & 3,36 & 3,34 \\
\hline 28 & 3,49 & 2,62 & 3,06 & 2,96 & 3,09 & 3,58 & 3,05 & 2,90 & 2,49 & 1,65 & 1,70 & 1,78 & 1,43 & 1,28 & 1,29 & 1,42 & 1,09 & 1,00 \\
\hline 30 & 0,11 & 0,14 & 0,13 & 0,14 & 0,13 & 0,10 & 0,17 & 0,16 & 0,13 & 0,11 & 0,09 & 0,32 & 0,84 & 0,82 & 0,65 & 1,82 & 1,99 & 2,15 \\
\hline 47 & 1,97 & 1,66 & 1,65 & 1,89 & 2,40 & 2,08 & 1,84 & 1,93 & 1,69 & 1,53 & 1,60 & 1,26 & 0,93 & 0,97 & 0,82 & 0,93 & 0,86 & 0,83 \\
\hline 68 & 1,99 & 1,82 & 1,81 & 1,57 & 1,87 & 1,61 & 1,36 & 1,35 & 1,10 & 1,17 & 1,34 & 1,34 & 1,18 & 0,87 & 0,85 & 0,80 & 0,68 & 0,73 \\
\hline 71 & 2,25 & 2,54 & 2,73 & 3,11 & 3,64 & 3,69 & 4,22 & 4,97 & 4,48 & 3,92 & 4,19 & 3,68 & 3,93 & 3,55 & 3,36 & 3,70 & 3,65 & 3,83 \\
\hline 72 & 2,72 & 2,54 & 2,94 & 3,31 & 3,86 & 3,69 & 4,03 & 4,05 & 3,79 & 3,61 & 3,69 & 3,75 & 3,34 & 3,20 & 2,65 & 2,89 & 2,78 & 2,51 \\
\hline 73 & 1,62 & 1,45 & 1,74 & 1,96 & 1,88 & 1,93 & 2,40 & 2,28 & 2,02 & 2,39 & 1,94 & 1,31 & 1,37 & 1,06 & 1,22 & 1,99 & 2,72 & 2,75 \\
\hline 84 & 0,32 & 0,33 & 0,33 & 0,38 & 0,42 & 0,42 & 0,40 & 0,38 & 0,37 & 0,42 & 0,42 & 0,41 & 0,44 & 0,36 & 0,37 & 0,37 & 0,36 & 0,30 \\
\hline 85 & 0,46 & 0,42 & 0,46 & 0,35 & 0,40 & 0,38 & 0,39 & 0,49 & 0,30 & 0,31 & 0,31 & 0,30 & 0,30 & 0,30 & 0,32 & 0,41 & 0,44 & 0,48 \\
\hline 87 & 1,52 & 1,50 & 1,70 & 1,20 & 0,94 & 0,69 & 0,74 & 0,67 & 0,60 & 0,82 & 0,87 & 1,03 & 1,12 & 0,78 & 0,68 & 0,62 & 0,65 & 0,67 \\
\hline
\end{tabular}

Fonte: Resultados da Pesquisa.

O índice de vantagem comparativa revelada simétrica, que varia de -1 a +1 , expressa uma vantagem comparativa quando o indicador for positivo e uma desvantagem se for negativo. A tabela 4, a seguir, revela os produtos que possuem essas vantagens, e se refere ao estado de Minas Gerais em relação ao Brasil.

Os produtos com vantagem comparativa revelada simétrica, para todo o período de análise, foram os capítulos 09 (com índices mais elevados, entre 0,60 e 0,73), $26,28,71,72$ e 73 . De outro modo, os produtos que apresentaram desvantagem comparativa revelada simétrica, para todos os anos, foram 02, 12, 17, 84 e 85.

Observou-se, também, que os capítulos 47 e 68, apresentaram uma vantagem até 2008 e 2009, respectivamente, e nos anos seguintes, seus índices configuraram uma desvantagem. De maneira contrária, o capítulo 30 refletiu desvantagem até 2011, e posteriormente, de 2012 a 2014, uma vantagem. Desagregando este produto em oito dígitos (NCM) verificou-se que "Medicamentos que contenham insulina, em doses" (código 30043100), produto da indústria química de alta tecnologia, ou seja, produto manufaturado, obteve um percentual de 81,27\%, em média, nestes últimos três anos. Sendo, deste modo, um fator relevante para o estado, demonstrando uma evolução neste setor industrial. 
Tabela 4 - Índice de vantagem comparativa revelada simétrica, por grupo de capítulos, de Minas Gerais em relação ao Brasil, 1997-2014

\begin{tabular}{|c|c|c|c|c|c|c|c|c|c|c|c|c|c|c|c|c|c|c|}
\hline Cap. & 1997 & 1998 & 1999 & 2000 & 2001 & 2002 & 2003 & 2004 & 2005 & 2006 & 2007 & 2008 & 2009 & 2010 & 2011 & 2012 & 2013 & 2014 \\
\hline 02 & $-0,91$ & $-0,90$ & $-0,84$ & $-0,71$ & $-0,54$ & $-0,48$ & $-0,46$ & $-0,47$ & $-0,48$ & $-0,30$ & $-0,32$ & $-0,44$ & $-0,35$ & $-0,46$ & $-0,50$ & $-0,40$ & $-0,39$ & $\begin{array}{l}-0,38 \\
\end{array}$ \\
\hline 09 & 0,62 & 0,60 & 0,61 & 0,66 & 0,72 & 0,71 & 0,73 & 0,73 & 0,73 & 0,72 & 0,72 & 0,70 & 0,70 & 0,66 & 0,62 & 0,64 & 0,64 & 0,66 \\
\hline 12 & $-0,71$ & $-0,52$ & $-0,53$ & $-0,56$ & $-0,59$ & $-0,41$ & $-0,40$ & $-0,43$ & $-0,28$ & $-0,42$ & $-0,75$ & $-0,76$ & $-0,63$ & $-0,73$ & $-0,78$ & $-0,68$ & $-0,57$ & $-0,61$ \\
\hline 17 & $-0,65$ & $-0,81$ & $-0,70$ & $-0,88$ & $-0,61$ & $-0,42$ & $-0,37$ & $-0,34$ & $-0,29$ & $-0,30$ & $-0,29$ & $-0,34$ & $-0,28$ & $-0,34$ & $-0,30$ & $-0,16$ & $-0,19$ & $-0,16$ \\
\hline 25 & $-0,17$ & $-0,25$ & $-0,05$ & $-0,02$ & $-0,11$ & $-0,09$ & 0,06 & $-0,04$ & $-0,02$ & $-0,05$ & $-0,05$ & $-0,04$ & 0,10 & 0,11 & 0,15 & 0,30 & 0,33 & 0,34 \\
\hline 26 & 0,53 & 0,56 & 0,58 & 0,62 & 0,66 & 0,67 & 0,61 & 0,57 & 0,53 & 0,54 & 0,56 & 0,51 & 0,57 & 0,48 & 0,47 & 0,52 & 0,54 & 0,54 \\
\hline 28 & 0,56 & 0,45 & 0,51 & 0,49 & 0,51 & 0,56 & 0,51 & 0,49 & 0,43 & 0,24 & 0,26 & 0,28 & 0,18 & 0,12 & 0,13 & 0,17 & 0,04 & 0,00 \\
\hline 30 & $-0,79$ & $-0,76$ & $-0,77$ & $-0,75$ & $-0,78$ & $-0,81$ & $-0,71$ & $-0,73$ & $-0,78$ & $-0,80$ & $-0,83$ & $-0,51$ & $-0,08$ & $-0,10$ & $-0,21$ & 0,29 & 0,33 & 0,36 \\
\hline 47 & 0,33 & 0,25 & 0,25 & 0,31 & 0,41 & 0,35 & 0,29 & 0,32 & 0,26 & 0,21 & 0,23 & 0,12 & $-0,03$ & $-0,02$ & $-0,10$ & $-0,03$ & $-0,07$ & $-0,10$ \\
\hline 68 & 0,33 & 0,29 & 0,29 & 0,22 & 0,30 & 0,23 & 0,15 & 0,15 & 0,05 & 0,08 & 0,14 & 0,14 & 0,08 & $-0,07$ & $-0,08$ & $-0,11$ & $-0,19$ & $-0,16$ \\
\hline 71 & 0,39 & 0,44 & 0,46 & 0,51 & 0,57 & 0,57 & 0,62 & 0,66 & 0,63 & 0,59 & 0,61 & 0,57 & 0,59 & 0,56 & 0,54 & 0,57 & 0,57 & 0,59 \\
\hline 72 & 0,46 & 0,43 & 0,49 & 0,54 & 0,59 & 0,57 & 0,60 & 0,60 & 0,58 & 0,57 & 0,57 & 0,58 & 0,54 & 0,52 & 0,45 & 0,49 & 0,47 & 0,43 \\
\hline 73 & 0,24 & 0,18 & 0,27 & 0,33 & 0,31 & 0,32 & 0,41 & 0,39 & 0,34 & 0,41 & 0,32 & 0,14 & 0,16 & 0,03 & 0,10 & 0,33 & 0,46 & 0,47 \\
\hline 84 & $-0,52$ & $-0,50$ & $-0,50$ & $-0,45$ & $-0,40$ & $-0,41$ & $-0,43$ & $-0,45$ & $-0,46$ & $-0,41$ & $-0,41$ & $-0,42$ & $\begin{array}{c}-0,39 \\
\end{array}$ & $-0,47$ & $-0,46$ & $-0,45$ & $-0,47$ & $-0,54$ \\
\hline 85 & $-0,37$ & $-0,41$ & $-0,37$ & $-0,48$ & $-0,43$ & $-0,45$ & $-0,44$ & $-0,34$ & $-0,54$ & $-0,53$ & $-0,52$ & $-0,54$ & $-0,54$ & $-0,54$ & $-0,52$ & $-0,42$ & $-0,39$ & $-0,35$ \\
\hline 87 & 0,21 & 0,20 & 0,26 & 0,09 & $-0,03$ & $-0,18$ & $-0,15$ & $-0,20$ & $-0,25$ & $-0,10$ & $-0,07$ & 0,01 & 0,06 & $-0,13$ & $-0,19$ & $-0,23$ & $-0,21$ & $-0,20$ \\
\hline
\end{tabular}

Fonte: Resultados da Pesquisa.

Ademais, os capítulos 25 e 87 apresentaram oscilações em seu índice, predominando uma desvantagem. Nota-se, que os resultados de ambas as tabelas (4 e 5) tem o mesmo significado, porém os valores dos índices são distintos, devido ao ajuste de assimetria do índice de VCR.

A tabela 5 se refere às vantagens comparativas reveladas de Minas Gerais em relação ao mundo. Verifica-se que o estado apresentou vantagem comparativa nos seguintes capítulos: 09, 12, 26, 28, 47, 68, 71 e 72, para todo o período. Além do mais, os capítulos 17 e 25 também apresentaram vantagens comparativas, exceto em 2000 e 1997/ 1998, respectivamente. Opondo-se, a este resultado, os capítulos 30, 84 e 85, possuem desvantagem comparativa para todos os anos. Os demais capítulos (02, 73 e 87) oscilaram no período.

Tabela 5 - Índice de vantagem comparativa revelada, por grupo de capítulos, de Minas Gerais em relação ao mundo, 1997-2014

\begin{tabular}{l|c|c|c|c|c|c|c|c|c|c|c|c|c|c|c|c|c|c}
\hline Cap. & 1997 & 1998 & 1999 & 2000 & 2001 & 2002 & 2003 & 2004 & 2005 & 2006 & 2007 & 2008 & 2009 & 2010 & 2011 & 2012 & 2013 & 2014 \\
\hline 02 & 0,16 & 0,16 & 0,37 & 0,79 & 1,88 & 2,22 & 2,58 & 3,02 & 3,14 & 4,67 & 5,12 & 3,48 & 4,03 & 3,18 & 2,59 & 3,21 & 3,65 & 2,58 \\
\hline
\end{tabular}




\begin{tabular}{|c|c|c|c|c|c|c|c|c|c|c|c|c|c|c|c|c|c|c|}
\hline 09 & 70,53 & 58,78 & 70,81 & 63,39 & 67,74 & 83,87 & 71,95 & 72,50 & 74,75 & 71,99 & 122,97 & 61,49 & 59,32 & 50,72 & 47,70 & 43,80 & 38,43 & 45,52 \\
\hline 12 & 1,87 & 3,41 & 3,02 & 3,61 & 3,56 & 5,88 & 6,28 & 6,34 & 8,11 & 6,05 & 1,98 & 1,71 & 3,35 & 1,77 & 1,64 & 2,36 & 4,60 & 2,48 \\
\hline 17 & 2,45 & 1,42 & 2,76 & 0,68 & 3,59 & 5,73 & 5,59 & 6,24 & 7,66 & 9,43 & 10,26 & 6,65 & 10,73 & 10,40 & 10,24 & 12,30 & 11,78 & 0,0 \\
\hline 25 & 0,71 & 0,73 & 1,37 & 1,92 & 1,34 & 1,43 & 2,25 & 1,67 & 1,63 & 1,61 & 1,80 & 1,26 & 1,76 & 1,75 & 1,62 & 2,40 & 2,75 & 2,40 \\
\hline 26 & 0,94 & 69 & 57,44 & 3,04 & 62,80 & 70,00 & 51,27 & 38,76 & 31,11 & 29,48 & 37,38 & 34,25 & 36,98 & 33,51 & 31,49 & 31,39 & 35,95 & 20 , \\
\hline 28 & 4,17 & 3,20 & 4,37 & 4,67 & 4,04 & 4,44 & 4,57 & 4,14 & 3,41 & 2,86 & 2,95 & 2,86 & 2,66 & 2,20 & 2,29 & 2,44 & 1,82 & 2, \\
\hline 30 & 0,02 & 0,03 & 0,04 & 0,04 & 0,03 & 0,02 & 0,02 & 0,02 & 0,02 & 0,02 & 0,01 & 0,05 & 0,16 & 0,16 & 0,13 & 0,38 & 0,43 & 0,36 \\
\hline 47 & 10,31 & 9,78 & 12,98 & 13,57 & 15,65 & 12,12 & 13,56 & 11,66 & 10,69 & 10,46 & 10,31 & 8,73 & 7,58 & 7,19 & 5,39 & 6,13 & 6,76 & 3,5 \\
\hline 68 & 3,44 & 3,27 & 3,46 & 3,50 & 3,82 & 3,52 & 2,77 & 3,04 & 2,59 & 3,12 & 3,21 & 2,41 & 2,17 & 1,63 & 1,32 & 1,28 & 1,24 & $1,6 \mathrm{~s}$ \\
\hline 71 & 1,58 & 1,38 & 1,65 & 1,74 & 1,82 & 2,05 & 1,77 & 1,95 & 1,61 & 1,61 & 1,88 & 1,40 & 1,86 & 1,52 & 1,23 & 1,61 & 1,47 & 1,1 \\
\hline 72 & 7,82 & 7,38 & 9,27 & 10,45 & 9,83 & 10,70 & 11,67 & 9,91 & 9,63 & 8,09 & 6,79 & 7,27 & 6,31 & 5,04 & 4,42 & 4,98 & 4,26 & 3, \\
\hline 73 & 1,28 & 1,05 & 1,25 & 1,45 & 1,40 & 1,47 & 1,46 & 1,42 & 1,18 & 1,39 & 0,92 & 0,71 & 0,80 & 0,46 & 0,47 & 0,79 & 1,10 & $\overline{1,8}$ \\
\hline 84 & 0,18 & 0,18 & 0,18 & 0,20 & 0,21 & 0,19 & 0,21 & 0,21 & 0,22 & 0,25 & 0,21 & 0,20 & 0,18 & 0,16 & 0,17 & 0,17 & 0,16 & 0,1 \\
\hline 85 & 0,12 & 0,11 & 0,13 & 0,12 & 0,16 & 0,14 & 0,13 & 0,13 & 0,10 & 0,11 & 0,10 & 0,09 & 0,08 & 0,06 & 0,06 & 0,07 & 0,07 & 0,0 \\
\hline 87 & 1,32 & 1,38 & 1,21 & 1,04 & 0,75 & 0,46 & 0,57 & 0,57 & 0,61 & 0,80 & 0,75 & 0,87 & 0,83 & 0,60 & 0,49 & 0,38 & 0,47 & 0,3 \\
\hline
\end{tabular}

Fonte: Resultados da Pesquisa.

Conforme a tabela 6 percebe-se, de forma agregada, que o comércio de Minas Gerais se caracteriza em inter-indústria para todos os anos, ou seja, baseado na teoria de Hecksher-Ohlin. Desta forma, seu índice varia de zero a um, e os resultados do estado apresentaram valores mais próximos de zero, refletindo as vantagens comparativas entre economias de diferentes dotações de fatores.

Comparativamente, o comércio do Brasil, para todos os setores, assumiu um caráter mais intra-indústria, ou próximo dele, pois seus valores estiveram acima de 0,41. Destaque para o período de 2006 a 2008, nos quais esse índice esteve acima de 0,5 , isto é, o fluxo de comércio exterior foi baseado na nova teoria do coméncio internacional, supondo concorrência monopolística, diferenciação dos produtos, economias de escala. Ou seja, o contrário do que postula as teorias clássicas, baseada nas vantagens comparativas. Desta forma, o desempenho agregado nacional foi superior ao do estado, pois seus produtos são mais diversificados, com certo grau de industrialização (semimanufaturados e/ ou manufaturados) e, que, exigem maior transformação, isto é, produtos mais elaborados.

Porém, verifica-se uma queda neste indicador, a partir de 2009, reflexo da crise do Subprime nos EUA (2008), bem como de uma provável tendência de reprimarização, isto é, a ocorrência de uma desindustrialização no país. De 2012 a 2014, os três principais produtos exportados, no Brasil, foram os capítulos: 09) minérios, escórias e cinzas; 12) sementes e frutos oleaginosos, etc. e; 27) combustíveis minerais, etc. Fazendo um desdobramento destes capítulos em 
oito dígitos (NCM), verificou-se que, em média (2012 a 2014), "minérios de ferro não aglomerados e seus concentrados" (26011100, produtos básicos) com 9,81\%; "óleos brutos de petróleo" (27090010, produtos básicos) 7,0\% e; "soja, mesmo triturada, exceto para semeadura" (12019000, produtos básicos) 8,96\%, ou seja, composto, essencialmente, por bens primários.

Tabela 6 - Índice de Comércio Intra-indústria, agregado, de Minas Gerais e do Brasil, 1997-2014

\begin{tabular}{l|c|c|c|c|c|c|c|c|c|c|c|c|c|c|c|c|c|c}
\hline Descrição & 1997 & 1998 & 1999 & 2000 & 2001 & 2002 & 2003 & 2004 & 2005 & 2006 & 2007 & 2008 & 2009 & 2010 & 2011 & 2012 & 2013 & 2014 \\
\hline MG & 0,29 & 0,33 & 0,28 & 0,29 & 0,29 & 0,25 & 0,25 & 0,24 & 0,22 & 0,25 & 0,24 & 0,25 & 0,22 & 0,21 & 0,17 & 0,18 & 0,18 & 0,17 \\
\hline Brasil & 0,45 & 0,47 & 0,45 & 0,46 & 0,47 & 0,47 & 0,47 & 0,45 & 0,49 & 0,52 & 0,52 & 0,50 & 0,49 & 0,48 & 0,46 & 0,46 & 0,41 & 0,42 \\
\hline
\end{tabular}

Fonte: Resultados da Pesquisa.

De outra forma, o índice de comércio intra-indústria no estado de Minas Gerais, ao nível de cada produto, está ilustrado tabela 7. Nota-se que o comércio interindústria prevalece, para todo o período, em grande parte dos capítulos selecionados como: 02, 09, 12, 17, 26, 28, 47, 68 (exceto em 2013), 71 e 72, destes, os que possuem os menores índices, ou seja, próximos de zero são: 09 (café, chá, mate e especiarias) e 47 (Pastas de madeira ou de outras matérias fibrosas celulósicas etc.), indicando poucas importações destes produtos no estado.

Tabela 7 - Índice de comércio intra-indústria, por grupo de capítulos, de Minas

Gerais, 1997-2014

\begin{tabular}{l|l|l|l|l|l|l|l|l|l|l|l|l|l|l|l|l|l|l|l}
\hline Código & 1997 & 1998 & 1999 & 2000 & 2001 & 2002 & 2003 & 2004 & 2005 & 2006 & 2007 & 2008 & 2009 & 2010 & 2011 & 2012 & 2013 & 2014 \\
\hline 02 & 0,42 & 0,30 & 0,10 & 0,06 & 0,02 & 0,01 & 0,00 & 0,00 & 0,00 & 0,00 & 0,00 & 0,00 & 0,00 & 0,00 & 0,00 & 0,01 & 0,00 & 0,00 \\
\hline 09 & 0,00 & 0,00 & 0,00 & 0,00 & 0,00 & 0,01 & 0,02 & 0,03 & 0,01 & 0,00 & 0,00 & 0,00 & 0,00 & 0,00 & 0,00 & 0,00 & 0,00 & 0,00 \\
\hline 12 & 0,05 & 0,06 & 0,06 & 0,03 & 0,04 & 0,04 & 0,01 & 0,01 & 0,01 & 0,02 & 0,06 & 0,03 & 0,02 & 0,04 & 0,02 & 0,01 & 0,01 & 0,01 \\
\hline 17 & 0,07 & 0,20 & 0,18 & 0,65 & 0,16 & 0,06 & 0,06 & 0,06 & 0,04 & 0,03 & 0,02 & 0,01 & 0,00 & 0,00 & 0,00 & 0,00 & 0,02 & 0,05 \\
\hline 25 & 0,79 & 0,92 & 0,93 & 0,98 & 0,97 & 0,98 & 0,99 & 0,91 & 0,87 & 0,87 & 0,99 & 0,30 & 0,88 & 0,96 & 0,89 & 0,95 & 0,89 & 0,89 \\
\hline 26 & 0,11 & 0,09 & 0,10 & 0,08 & 0,07 & 0,07 & 0,10 & 0,11 & 0,11 & 0,15 & 0,13 & 0,06 & 0,03 & 0,03 & 0,02 & 0,03 & 0,02 & 0,02 \\
\hline 28 & 0,27 & 0,29 & 0,22 & 0,25 & 0,35 & 0,32 & 0,35 & 0,33 & 0,26 & 0,29 & 0,29 & 0,33 & 0,30 & 0,22 & 0,21 & 0,31 & 0,37 & 0,45 \\
\hline 30 & 0,52 & 0,70 & 0,67 & 0,56 & 0,45 & 0,44 & 0,61 & 0,92 & 0,68 & 0,32 & 0,31 & 0,77 & 0,66 & 0,81 & 0,95 & 0,53 & 0,55 & 0,58 \\
\hline 47 & 0,00 & 0,01 & 0,00 & 0,00 & 0,00 & 0,00 & 0,00 & 0,00 & 0,01 & 0,01 & 0,01 & 0,01 & 0,00 & 0,00 & 0,00 & 0,01 & 0,01 & 0,01 \\
\hline 68 & 0,21 & 0,17 & 0,15 & 0,13 & 0,13 & 0,12 & 0,12 & 0,12 & 0,08 & 0,07 & 0,08 & 0,08 & 0,11 & 0,14 & 0,16 & 0,30 & 0,51 & 0,44 \\
\hline 71 & 0,01 & 0,01 & 0,01 & 0,06 & 0,06 & 0,01 & 0,01 & 0,00 & 0,00 & 0,01 & 0,00 & 0,01 & 0,00 & 0,00 & 0,03 & 0,02 & 0,02 & 0,02 \\
\hline 72 & 0,09 & 0,09 & 0,05 & 0,04 & 0,09 & 0,06 & 0,03 & 0,04 & 0,06 & 0,06 & 0,08 & 0,10 & 0,10 & 0,13 & 0,07 & 0,10 & 0,08 & 0,09 \\
\hline
\end{tabular}




\begin{tabular}{l|l|l|l|l|l|l|l|l|l|l|l|l|l|l|l|l|l|l}
\hline 73 & 0,67 & 0,68 & 0,47 & 0,45 & 0,68 & 0,51 & 0,32 & 0,38 & 0,43 & 0,45 & 0,71 & 0,82 & 0,73 & 1,00 & 0,94 & 0,83 & 0,66 & 0,53 \\
\hline 84 & 0,32 & 0,41 & 0,34 & 0,55 & 0,49 & 0,51 & 0,76 & 0,77 & 0,73 & 0,74 & 0,59 & 0,55 & 0,48 & 0,48 & 0,46 & 0,49 & 0,43 & 0,40 \\
\hline 85 & 0,46 & 0,51 & 0,54 & 0,61 & 0,55 & 0,73 & 0,71 & 0,81 & 0,74 & 0,69 & 0,54 & 0,49 & 0,47 & 0,42 & 0,40 & 0,43 & 0,41 & 0,42 \\
\hline 87 & 0,85 & 0,95 & 0,81 & 0,90 & 0,85 & 0,96 & 0,89 & 0,80 & 0,77 & 0,76 & 0,74 & 0,99 & 0,86 & 0,84 & 0,73 & 0,59 & 0,61 & 0,57 \\
\hline
\end{tabular}

Fonte: Resultados da Pesquisa.

De forma contrária, os capítulos com maiores índices foram o 25 (Sal; enxofre; terras e pedras; gesso, cal e cimento), exceto em 2008, e 87 (Veículos automóveis, tratores, ciclos e outros veículos terrestres, suas partes e acessórios) constituindo um comércio do tipo intra-indústria, alicerçado na diferenciação dos produtos. Os demais apresentaram certa variação.

Em relação ao país, o índice de comércio intra-indústria, ao nível de cada produto, obteve certa volatilidade em alguns setores, como mostra a tabela 10. Porém, configura-se, em sua maioria, um comércio inter-indústria. Em todo período analisado, os capítulos 25, 28, 73, 84 e 87 apresentaram elevado grau de comércio intra-indústria.

De forma semelhante ao resultado do estado, no Brasil, o capítulo 09 "café, chá, mate e especiarias" apresentou o menor índice. Deste modo, a ocorrência de comércio inter-indústria acentua a manutenção de uma especialização em que, sobretudo, em Minas Gerais e, em menor escala, no país, evidencia as diferenças de dotações de fatores entre as distintas nações. Em outras palavras, o estado mineiro é mais competitivo nos segmentos de produtos baseados em recursos naturais.

Tabela 8 - Índice de comércio intra-indústria, por grupo de capítulos, do Brasil, 1997-2014

\begin{tabular}{l|l|l|l|l|l|l|l|l|l|l|l|l|l|l|l|l|l|l}
\hline Código & 1997 & 1998 & 1999 & 2000 & 2001 & 2002 & 2003 & 2004 & 2005 & 2006 & 2007 & 2008 & 2009 & 2010 & 2011 & 2012 & 2013 & 2014 \\
\hline 02 & 0,31 & 0,27 & 0,11 & 0,15 & 0,05 & 0,06 & 0,04 & 0,03 & 0,03 & 0,02 & 0,02 & 0,02 & 0,03 & 0,03 & 0,04 & 0,05 & 0,05 & 0,06 \\
\hline 09 & 0,02 & 0,02 & 0,02 & 0,02 & 0,04 & 0,03 & 0,03 & 0,03 & 0,02 & 0,01 & 0,02 & 0,02 & 0,02 & 0,02 & 0,02 & 0,02 & 0,03 & 0,03 \\
\hline 12 & 0,22 & 0,21 & 0,15 & 0,15 & 0,12 & 0,14 & 0,12 & 0,05 & 0,05 & 0,03 & 0,03 & 0,03 & 0,03 & 0,03 & 0,02 & 0,04 & 0,03 & 0,04 \\
\hline 17 & 0,08 & 0,07 & 0,05 & 0,07 & 0,03 & 0,02 & 0,02 & 0,02 & 0,01 & 0,01 & 0,02 & 0,02 & 0,01 & 0,01 & 0,01 & 0,02 & 0,02 & 0,02 \\
\hline 25 & 0,91 & 0,98 & 0,83 & 0,84 & 0,78 & 0,74 & 0,75 & 0,79 & 0,68 & 0,62 & 0,73 & 0,66 & 0,88 & 1,00 & 0,83 & 0,83 & 0,90 & 0,92 \\
\hline 26 & 0,22 & 0,15 & 0,20 & 0,19 & 0,17 & 0,16 & 0,17 & 0,23 & 0,18 & 0,26 & 0,23 & 0,13 & 0,11 & 0,08 & 0,06 & 0,06 & 0,07 & 0,08 \\
\hline 28 & 0,91 & 0,91 & 0,95 & 0,99 & 0,90 & 0,89 & 0,98 & 0,94 & 0,94 & 0,81 & 0,82 & 0,98 & 0,89 & 0,79 & 0,80 & 0,89 & 0,92 & 0,78 \\
\hline 30 & 0,26 & 0,28 & 0,27 & 0,27 & 0,27 & 0,29 & 0,31 & 0,33 & 0,38 & 0,39 & 0,35 & 0,37 & 0,39 & 0,35 & 0,37 & 0,36 & 0,34 & 0,35 \\
\hline 47 & 0,26 & 0,29 & 0,26 & 0,26 & 0,26 & 0,26 & 0,17 & 0,20 & 0,19 & 0,16 & 0,14 & 0,13 & 0,14 & 0,14 & 0,14 & 0,13 & 0,12 & 0,12 \\
\hline 68 & 0,63 & 0,63 & 0,58 & 0,52 & 0,54 & 0,44 & 0,40 & 0,36 & 0,34 & 0,31 & 0,36 & 0,46 & 0,46 & 0,52 & 0,65 & 0,70 & 0,67 & 0,63 \\
\hline
\end{tabular}




\begin{tabular}{l|l|l|l|l|l|l|l|l|l|l|l|l|l|l|l|l|l|l}
\hline 71 & 0,28 & 0,32 & 0,42 & 0,53 & 0,62 & 0,42 & 0,39 & 0,41 & 0,44 & 0,46 & 0,52 & 0,52 & 0,35 & 0,39 & 0,38 & 0,33 & 0,29 & 0,31 \\
\hline 72 & 0,22 & 0,25 & 0,21 & 0,24 & 0,28 & 0,17 & 0,15 & 0,15 & 0,18 & 0,27 & 0,32 & 0,41 & 0,49 & 0,72 & 0,50 & 0,51 & 0,56 & 0,52 \\
\hline 73 & 0,94 & 0,85 & 1,00 & 0,97 & 0,99 & 0,89 & 0,93 & 0,88 & 0,91 & 0,93 & 0,92 & 0,88 & 0,84 & 0,65 & 0,65 & 0,63 & 0,56 & 0,71 \\
\hline 84 & 0,59 & 0,58 & 0,61 & 0,64 & 0,61 & 0,68 & 0,84 & 0,91 & 0,91 & 0,89 & 0,77 & 0,66 & 0,55 & 0,56 & 0,59 & 0,57 & 0,53 & 0,57 \\
\hline 85 & 0,35 & 0,36 & 0,39 & 0,49 & 0,50 & 0,61 & 0,64 & 0,56 & 0,69 & 0,66 & 0,60 & 0,51 & 0,50 & 0,37 & 0,33 & 0,32 & 0,28 & 0,27 \\
\hline 86 & 0,48 & 0,41 & 0,17 & 0,45 & 0,67 & 0,62 & 0,88 & 0,61 & 0,90 & 0,93 & 0,84 & 0,64 & 0,93 & 0,70 & 0,51 & 0,24 & 0,48 & 0,23 \\
\hline 87 & 0,93 & 0,94 & 0,98 & 0,91 & 0,92 & 0,74 & 0,59 & 0,55 & 0,54 & 0,63 & 0,76 & 0,93 & 0,85 & 0,83 & 0,76 & 0,74 & 0,77 & 0,67 \\
\hline
\end{tabular}

Fonte: Resultados da Pesquisa.

\section{CONSIDERAÇÕES FINAIS}

Com o intuito de analisar a especialização e o fluxo de comércio exterior do estado de Minas Gerais, foram calculados distintos indicadores econômicos. Constatou-se que o estado, apesar de certa diversificação, concentra-se em poucos produtos, sobretudo, agrícolas, minerais e metais. Além disso, possui um padrão em sua pauta de exportações baseado em produtos intensivos em recursos naturais, fator abundante nesta região, propiciando vantagens comparativas em vários setores. Neste sentido, verificou-se que, prevalece em Minas Gerais, o comércio interindustrial, fundamentado nas vantagens comparativas, ocorrendo entre economias de diferentes dotações de fatores.

Dentre os 16 capítulos que compõem a pauta de exportações no estado, três deles apresentaram maior peso: 09) café, chá, mate e especiarias; 26) minérios, escórias e cinzas e; 72) ferro fundido, ferro e aço. Estes setores, juntos, representam uma parcela significativa do total exportado pelos mineiros no exterior. Deste modo, o setor primário, prevalece. Portanto, fornece matériaprima para indústria de transformação, sendo de baixo valor agregado, revelando que o estado de Minas Gerais ainda tem muito a desenvolver, apesar de alguns avanços.

Neste sentido, o capítulo 30 "produtos farmacêuticos", classificado como manufaturado, de alto valor agregado, apresentou tal evolução, sobretudo nos últimos anos do período. Assim, demonstra um pequeno progresso, possibilitando, mesmo em menor escala, uma alteração na estrutura produtiva do estado.

Desta forma, conclui-se que, as hipóteses propostas para este trabalho, foram confirmadas. Logo, o estado de Minas Gerais possui vantagens comparativas em produtos de baixo valor agregado e seu comércio é do tipo inter-indústria, baseado na teoria de Heckscher-Ohlin.

\section{REFERÊNCIAS}

BALASSA, B. Trade Liberalization and Reveled Comparative Advantage. Washington, DC: Banco Mundial, 1965. 
BRESSER PEREIRA, L. C.; MARCONI, N. Doença holandesa e desindustrialização. J ornal Valor Econômico, 25/ 11/2008. Disponível em: http:// www.bresserpereira.org.br/ Articles/ 2009/09.11.25.Doenca_holandesa e_desindustrializacao.pdf Acesso em: 10/05/2014

CANO, W. A desindustrialização no Brasil. Economia e Sociedade, Campinas, vol. 21, pag. 831-851, dez. 2012. Número especial. Disponível em: http:// centrocelsofurtado.org.br/ congresso2014/ arquivos/ file/ Artigo\%20Wilso n\%20Cano.pdf.Acesso em: 01/ 04/2014

CARVALHO, F. M. A. O Comportamento das Exportações Brasileiras e a Dinâmica do Complexo Agroindustrial. 1995, 126 p. Tese (Doutorado em Economia Agrária) - Escola Superior de Agricultura Luis Queiroz. Piracicaba, 1995.

FERREIRA, B. M.; PINTO, P. R. L. Análise do Fluxo Comencial do Estado do Rio Grande do Sul com a União Européia, sob a ótica do Comércio IntraIndústria e da Vantagem Comparativa Revelada para o Período de 1999 a 2005. 4o Encontro de Economia Gaúcha- EEG. Porto Alegre, 2008. Disponível em: 〈http://www.fee.rs.gov.br/4-encontro-economiagaucha/ trabalhos/macro-externo-sessao1-2.doc>Acesso em: 07 nov. 2014.

GONÇALVES, R. Economia Política Internacional: fundamentos teóricos e as relações internacionais do Brasil. Rio de J aneiro: Elsevier, 2005.

GONÇALVES, R. et al. A nova economia internacional: uma perspectiva brasileira. 2. ed. Rio de J aneiro: Campus, 1998.

GRUBEL, H. G.; LLOYD, P. J . Intra-industry trade: the theory and measurement of international trade in differentiated products. London: Macmillan, 1975.

HERMIDA, C.C.; XAVIER, C. L. Competitividade das exportações brasileiras a partir de parâmetros tecnológicos: uma análise de painel para 2004-2008. Ind. Econ. FEE, Pouso Alegre, vol.39, n¹, pag. 103-118, 2011. Disponível em: http:// revistas.fee.tche.br/ index.php/indicadores/article/viewFile/ 2476/ 2960 Acesso em: 05/ 05/2014

HIDALGO, A. B. Intensidades fatoriais na economia brasileira: novo teste empírico do teorema de Heckscher-Ohlin. Revista Brasileira de Economia, Brasil, 39, jan. $1985 . \quad$ Disponível em: <http:// bibliotecadigital.fgv.br/ ojs/index.php/rbe/ article/ view/ 336/ 7743> . Acesso em: 06 Nov. 2014.

KRUGMAN, P.; OBSTFELD, M. Economia internacional: teoria e política. 8. ed. São Paulo: Pearson Prentice Hall, 2010.

LAURSEN, K. Revealed comparative advantage and the alternatives as measures of international specialization. Working Paper, n.98-30, Copenhagen: Danish Research Unit for Industrial Dynamics, 1998. 
MAIA, J. M. Economia Internacional e comércio exterior. 10. ed. São Paulo: Atlas, 2006.

MARCONI, N. O desempenho do comércio exterior no período pós-crise. Boletim de Economia e Política Internacional, Brasília, vol. 13, pag. 3556, jan- abr 2013. Disponível em: http:// www.ipea.gov.br/ portal/images/stories/PDFs/boletim internacional/ 13 0515_boletim_internacional013.pdf. Acesso em: 09/03/2014

MINISTÉRIO DO DESENVOLVIMENTO, INDÚSTRIA E COMÉRCIO EXTERIOR - MDIC. Secretaria de Comércio Exterior (MDIC/SECEX). Dados sobre o comércio exterior brasileiro. Disponível em: $<\mathrm{http} / / /$ aliceweb.mdic.gov.br>. Acesso em: 2014.

SILVA, M; ILHA, A. da S. Avaliação do padrão de comércio Brasil-Argentina no período 1989-2001: uma ênfase no comércio intra-indústria. Revista de Integração Latino Americana (Rila), Santa Maria, v. 1, n. 1, p. 99-122, 2004.

SIQUEIRA, K. B.; PINHA, L. C. Vantagens Comparativas Reveladas e o Contexto do Brasil no Comércio Internacional de Lácteos. Informações Econômicas, SP, v. 42, n. 3, maio/jun. 2012. Disponível em: বtp:// ftp.sp.gov.br/ftpiea/ publicacoes/ IE/2012/ tec5-0612.pdf> Acesso em 22 out. 2014.

VASCONCELOS, C. R. F. O comércio Brasil-Mercosul na década de 90: uma análise pela ótica do comércio intra-indústria. Revista Brasileira de Economia, v. 57, n. 1, p. 283-313, 2003. Disponível em: <http:// www.scielo.br/ pdf/rbe/v57n1/a12v57n1.pdf> Acesso em 07 nov. 2014. 